Article

\title{
Micromechanism of the Dispersion Behavior of Polymer-Modified Rejuvenators in Aged Asphalt Material
}

\author{
Mingyu Zhao ${ }^{1}{ }^{\mathbb{D}}$, Fan Shen ${ }^{2}$ and Qingjun Ding ${ }^{1, *}$ \\ 1 State Key Laboratory of Silicate Materials for Architectures, Wuhan University of Technology, \\ Wuhan 430070, China; zmyzhaomingyu@whut.edu.cn \\ 2 School of Material Science and Engineering, Wuhan Institute of Technology, Wuhan 430073, China; \\ shenf@wit.edu.cn \\ * Correspondence: dingqj@whut.edu.cn; Tel.: +86-186-7230-6262
}

Received: 1 August 2018; Accepted: 6 September 2018; Published: 8 September 2018

Featured Application: This study of the dispersion behavior for polymer-modified rejuvenator would lay a foundation for the performance research and further recycling engineering practice of polymer-modified rejuvenated asphalt binders.

\begin{abstract}
Polymer-modified rejuvenator has a different composition and dispersion behavior to traditional rejuvenators. The objective of this study was to investigate the micromechanism of polymer-modified rejuvenators on the behavior of aged asphalt binder. Firstly, gel permeation chromatography (GPC) analysis was conducted to determine the dispersion effectiveness. Secondly, the dispersal behavior of polymer-modified rejuvenators was studied by means of atomic force microscopy (AFM) and scanning electron microscopy (SEM). Rheological, toughness-tenacity, and force-ductility analyses of the rejuvenated asphalt binder were additionally performed. The results indicate that the contacted asphaltenic micelles in aged asphalt binder were dispersed by dispersion agent in the polymer-modified rejuvenator, and that the dispersion ability of the polymer-modified rejuvenator was promoted to the commercial rejuvenator level. Additionally, the polymer-modified rejuvenator was found to improve the rejuvenated asphalt binder's resistance to deformation, through the formation of polymeric network structures in the asphalt binder. The results may be used to improve the performance of rejuvenated asphalt binder in recycled-pavement engineering.
\end{abstract}

Keywords: dispersion; aged asphalt binder; modified; rejuvenator; micromechanism; performance

\section{Introduction}

Rejuvenators, due to their rich maltene constituents and high permeation ability, can re-balance the composition of aged asphalt binders and have become the key material in pavement-recycling technology [1-3]. In recent years, many pavement materials have reached the end of their service life and have been abandoned in the city (Figure 1). Therefore, developing more effective and durable recycling technologies to rejuvenate this waste asphalt concrete is important for sustainable urban construction [4-6].

At present, the basic composition of the rejuvenator that is commonly used in asphalt pavement recycling is single component, being comprised of materials such as petroleum by-products, industrial oils, living waste, plant extract oils, etc., [7-12], the common feature of which is a high content of aromatics. Laboratory research and different engineering application results show that rejuvenators can restore the rheological and physical properties of binders [13-16]. Xiaokong Yu et al. studied the 
effect of two generic rejuvenators effect on asphalt binders through rheological property analyses. The result of this study showed that the two complex modulus master curves of virgin binder and rejuvenated binder almost overlapped at $12 \%$ rejuvenator content [17]. Additionally, Martins Zaumanis et al. conducted a comprehensive study to evaluate the use of different recycling agents on the properties of rejuvenated binders. The results of this research revealed that all six different agents selected in the study were able to reduce the kinematic viscosity of the aged binder at an intermediate temperature [18]. Many previous studies have indicated that rejuvenators merely soften aged asphalt binder and recover the rheological and physical properties to the level of the ordinary virgin asphalt, though do not significantly improve its performance $[19,20]$. Therefore, the function of rejuvenator for the improvement of the viscoelasticity and toughness of asphalt binder would be of significance for the durability of recycled pavement, especially given the present trend of using more reclaimed asphalt pavement in recycled mixtures, and the need for higher performance requirements of recycled pavement due to a likely increase in traffic volume in the future [21,22].
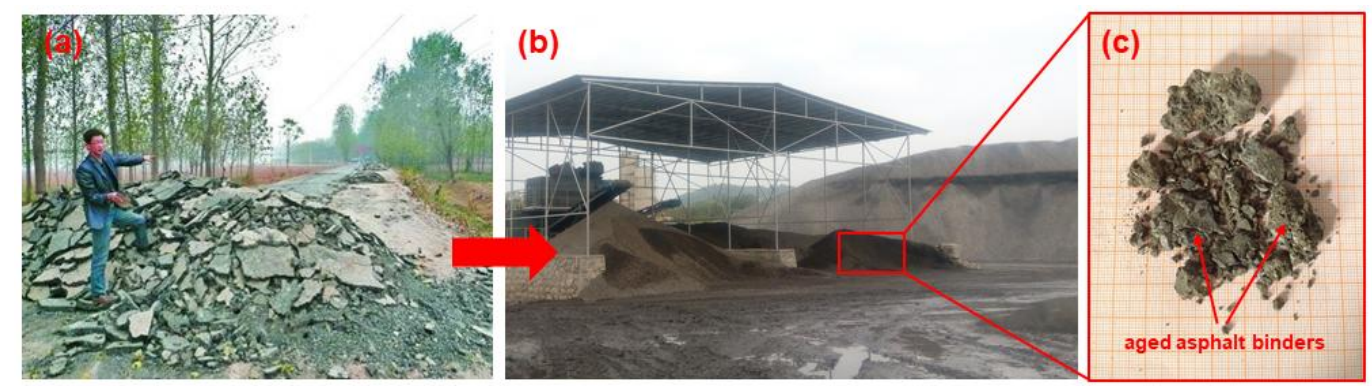

Figure 1. Pavement materials which have reached the end of their service life: (a) Waste asphalt concrete form old pavement; (b) Reclaimed asphalt pavement materials; (c) Aged asphalt binders covered with aggregate.

Studies on the modification of aged asphalt binder using a rejuvenating process have recently been receiving research attention. For example, Zhang et al. [23] demonstrated the feasibility of modifying aged asphalt binder by analyzing its features, as well as those of the rejuvenator and modifier. However, this study did not offer specific technical measures. Additionally, a United States patent [24] proposed a method in which a modifier, such as SBS, SBR, or rubber powder, is mixed with a rejuvenator directly during mixing of the asphalt binder in a plant, to achieve the modifying goals. However, in this patent the authors failed to list the technological means by which to ensure the effectiveness of the modifiers on aged asphalt binder. Modifiers require an extended period to disperse and swell in aged asphalt binder at high temperatures, and thus with a short mixing process it was difficult to obtain an anticipative modification effect. To date there are no effective methods to complete the rejuvenating and modifying process simultaneously.

The primary objective of this study is to investigate the effectiveness of polymer-modified rejuvenators on aged asphalt binder, including the two critical aspects of dispersion and performance. The dispersion behavior between the rejuvenator and aged asphalt binder was studied by measuring changes in the molecular weight distribution and micro-colloidal structure along the vertical axis. The effect of rejuvenation and modification on aged asphalt binder was also studied.

\section{Materials and Methods}

\subsection{Materials}

\subsubsection{Aged Asphalt Binder}

In this study, aged asphalt binder was prepared in the laboratory using a 60/80 penetration grade of virgin asphalt binder (AH-70). Firstly, the virgin asphalt binder was poured into circular plates (diameter $150 \mathrm{~mm}$, depth $30 \mathrm{~mm}$ ) to produce a film with a thickness of $8-10 \mathrm{~mm}$. The circular 
plates were then placed in an oven at a temperature of $155^{\circ} \mathrm{C}$ for $80 \mathrm{~h}$, being agitated every $30 \mathrm{~min}$ to ensure an even aging process, to produce the final aged asphalt binder. To compare the rejuvenating effectiveness of polymer-modified rejuvenators, a commercial modified asphalt binder (Oceanpower Technology Company, Shenzhen, China, Model No 1-D) was used in this study. The basic properties of virgin, aged asphalt binder and modified asphalt binder are presented in Table 1.

Table 1. Basic properties of virgin, aged and modified asphalt binder.

\begin{tabular}{ccccc}
\hline Sample & Penetration $\mathbf{( 0 . 1} \mathbf{~ m m})$ & Softening Point $\left({ }^{\circ} \mathbf{C}\right)$ & Ductility $25{ }^{\circ} \mathbf{C}(\mathbf{c m})$ & Viscosity $\mathbf{6 0}{ }^{\circ} \mathbf{C ~ ( P a \cdot s )}$ \\
\hline Virgin asphalt (AH-70) & 72.6 & 47.5 & 162 & 256 \\
Aged asphalt & 35.8 & 65.2 & 12.5 & 1285 \\
Modified asphalt binder (1-D) & 48.2 & 72.5 & 52.3 & 6370 \\
\hline
\end{tabular}

\subsubsection{Rejuvenators}

Three different rejuvenators were used in this study, including one commercial rejuvenator (CR) and two polymer-modified rejuvenators (MR-1 and MR-2). The CR, produced by Dongying Mingde Petroleum Technology Co., Ltd. (Dongying, China), is a common rejuvenating agent used for pavement-recycling engineering in China. In this study, CR was used for comparison with the polymer-modified rejuvenators. The polymer-modified rejuvenators were prepared with second-line extract oil (Hengtai Shuangfeng Chemical Factory, Loudi, China), C9 aromatics petroleum resin (Puyang Hengfeng Petrochemical industry, Puyang, China), Linear-type SBS (YH-791, SINOPEC Baling Company, Yueyang, China), stabilizing agent (Dibutyl phthalate) and dispersing agent (Methacrylate quaternary copolymer). MR-2 was the main rejuvenator investigated in this study, while MR-1, which did not contain a dispersing agent, was investigated for comparison with MR-2 in dispersion analysis.

The preparation process for polymer-modified rejuvenator is shown in Figure 2. Firstly, the extracted oil and petroleum resin are blended in a reactor at a temperature of $140{ }^{\circ} \mathrm{C}$ for $60 \mathrm{~min}$ (Figure 2a). Secondly, the SBS modifier and stabilizing agent are gradually added to a high-speed shearing machine at a temperature of $180^{\circ} \mathrm{C}$ for $30 \mathrm{~min}$ (Figure $2 \mathrm{~b}$ ). Thirdly, the dispersing agent is added to the same shearing machine, at a lower shearing rate, at a temperature of $170{ }^{\circ} \mathrm{C}$, for $5 \mathrm{~min}$ (Figure 2c). Finally, the mixture is kept at a temperature of $150^{\circ} \mathrm{C}$ for $30 \mathrm{~min}$ (Figure 2d). MR-1 was prepared using steps (a), (b), and (d), as depicted in Figure 2, and MR-2 was prepared using steps (a), (b), (c), and (d).

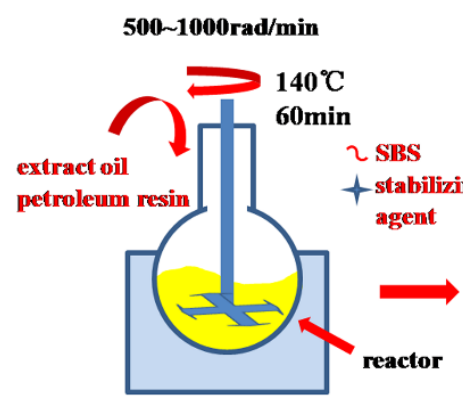

(a)

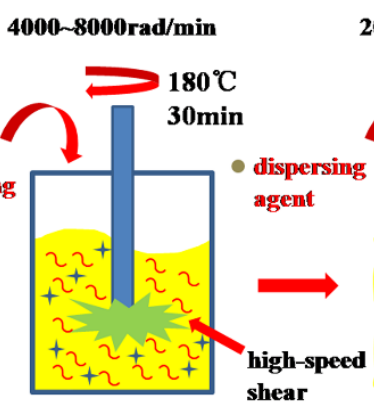

(b)
2000 3000 $\mathrm{rad} / \mathrm{min}$

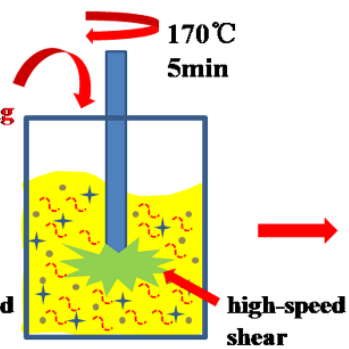

(c)

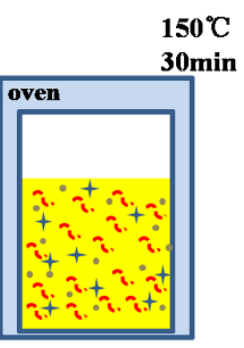

(d)

Figure 2. Preparation process of the polymer-modified rejuvenators: (a) blending the extracted oil and petroleum resin in reactor; (b) adding SBS modifier and stabilizing agent in high speed shearing machine; (c) adding dispersing agent in high speed shearing machine; (d) keeping the samples in oven.

In the aforementioned process, the stabilizing agent was used to prevent the phase segregation of the SBS modifier, and the dispersing agent (in the case of MR-2), which contains carboxyl and amino groups, was used to help evenly disperse the oil, the modifier, and the other rejuvenator components 
within the aged asphalt binder. The basic properties of the three rejuvenators are presented in Table 2, and the basic composition of the two rejuvenators prepared in the laboratory are presented in Table 3.

Table 2. Basic properties of the rejuvenators.

\begin{tabular}{ccccc}
\hline Sample & $\begin{array}{c}\text { Viscosity }\left(\mathbf{6 0}{ }^{\circ} \mathbf{C}\right) \\
\text { /Pa.s }\end{array}$ & $\begin{array}{c}\text { Viscosity }\left(\mathbf{1 3 5}{ }^{\circ} \mathbf{C}\right) \\
\text { /Pa.s }\end{array}$ & $\begin{array}{c}\text { Viscosity Ratio } \\
\text { by TOFT }\end{array}$ & $\begin{array}{c}\text { Mass Loss by } \\
\text { TOFT/\% }\end{array}$ \\
\hline CR & 1.72 & 0.31 & 2.65 & -3.02 \\
MR-1 & 16.31 & 5.36 & 2.03 & -2.18 \\
MR-2 & 8.21 & 2.21 & 1.16 & -2.60 \\
\hline
\end{tabular}

Table 3. Basic composition of the rejuvenators.

\begin{tabular}{cccccc}
\hline Sample & $\begin{array}{c}\text { Second-Line } \\
\text { Extract oil/wt.\% }\end{array}$ & $\begin{array}{c}\text { Petroleum } \\
\text { Resin/wt.\% }\end{array}$ & $\begin{array}{c}\text { Linear-Type } \\
\text { SBS/wt.\% }\end{array}$ & $\begin{array}{c}\text { Stabilizing } \\
\text { Agent/wt.\% }\end{array}$ & $\begin{array}{c}\text { Dispersing } \\
\text { Agent /wt.\% }\end{array}$ \\
\hline MR-1 & 49 & 5 & 40 & 6 & 0 \\
MR-2 & 40 & 5 & 40 & 6 & 9 \\
\hline
\end{tabular}

\subsection{Experiments}

\subsubsection{Specimen Preparation}

To study the dispersal behavior of different rejuvenators in aged asphalt binder, a laboratory method was developed as shown in Figure 3. The preparation process for the rejuvenated specimens at different depths was divided into four steps. Firstly, the aged asphalt binder was poured into a container (Figure 3a) with a depth of $35 \mathrm{~mm}$, and then the rejuvenator (10 g) was deposited evenly on the surface of the asphalt binder. Secondly, the container holding the aged asphalt binder and rejuvenator was placed in an oven at a temperature of $135^{\circ} \mathrm{C}$ for $6 \mathrm{~h}$, to initiate the dispersion process (Figure $3 b$ ). Thirdly, any rejuvenator that did not penetrate the asphalt binder was removed from the surface using a dropper at a temperature of $105^{\circ} \mathrm{C}$, and the sample was then gradually cooled to a temperature of $5{ }^{\circ} \mathrm{C}$ (Figure 3c). Lastly, the samples were removed from the container and cut into three slices-referred to as D1, D2, and D3-each with a thickness of $3 \mathrm{~mm}$, at a temperature of $5{ }^{\circ} \mathrm{C}$ (Figure 3d). Following these four steps, the slices were analyzed using gel permeation chromatography (GPC), atomic force microscopy (AFM), and scanning electron microscopy (SEM).
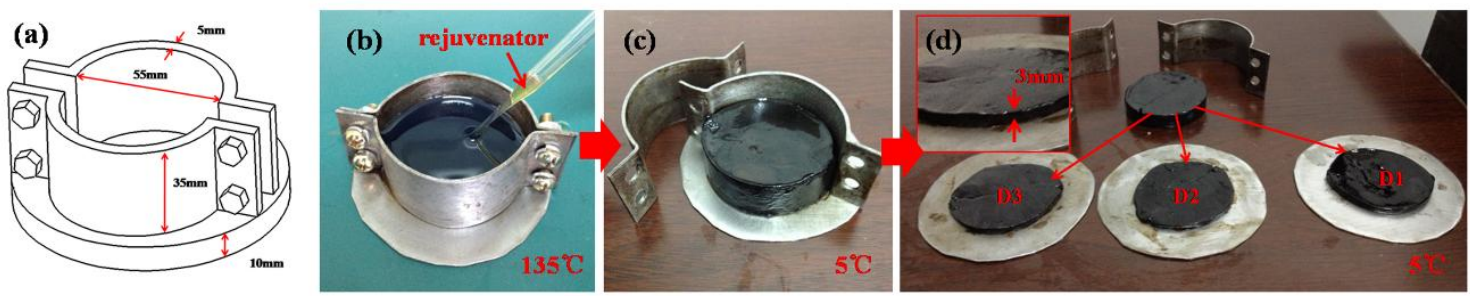

Figure 3. Preparation process of the specimens for dispersal behavior analysis: (a) appearance and dimension parameter of the container for aged asphalt binder; (b) the asphalt sample at the initial stage of dispersion process; (c) the asphalt sample that complete the dispersion process; (d) the slices samples which cut at $5{ }^{\circ} \mathrm{C}$.

To assess the performance of the rejuvenated asphalt binder, samples with different rejuvenator contents were also studied. The rejuvenator content of aged asphalt is commonly $4 \sim 8 \mathrm{wt} . \%$, and accordingly three different contents-3 wt. $\%, 6 \mathrm{wt} . \%$, and $9 \mathrm{wt} . \%$-were selected in this study to represent low, medium, and high levels of rejuvenator content, respectively. The aged asphalt binder was mixed with rejuvenator at a temperature of $165^{\circ} \mathrm{C}$ for $15 \mathrm{~min}$ to ensure a homogeneous system, and rheology, toughness, and tenacity were subsequently assessed. 


\subsubsection{Gel Permeation Chromatography Analysis}

GPC was used to analyze the molecular weight distribution of the rejuvenated asphalt binder at different depths. The measurements were carried out in LT-20A (Shimadzu, Kyoto, Japan) using a RID-10A detector, and two Agilent chromatographic columns (PLgel $5 \mu \mathrm{m}$ mixed-C, $4.6 \times 250 \mathrm{~mm}$ ) in series. The asphalt binder samples dissolved in tetrahydrofuran (THF), and the polystyrene nanospheres $(0.350 \mathrm{~mL} / \mathrm{min})$ was used as guide sample in GPC analysis. At least two replicates of each analysis were performed.

\subsubsection{Atomic Force Microscopy Analysis}

The microstructural characterization of asphalt binders was carried out using AFM, with an Asylum Research MFP-3D-classic AFM instrument (Oxford Instruments, Oxford, UK). A drop of hot, liquid asphalt binder sample was carefully placed onto a $76 \times 26 \times 1 \mathrm{~mm}$ glass slide, and then cooled to ambient temperature before being analyzed by AFM in tapping mode, at a temperature of $30^{\circ} \mathrm{C}$. At least two replicates of each analysis were performed, and 3D height images and 2D phase images $(20 \times 20 \mu \mathrm{m})$ were additionally acquired.

\subsubsection{Scanning Electron Microscopy Analysis}

SEM was used to characterize the surface morphology of rejuvenated asphalt binder with different rejuvenators. The SEM analysis was performed using a Quanta 450 instrument (FEI, Hillsboro, OR, USA). The asphalt binder sample was placed onto a tin-foil plate at a constant temperature of $135{ }^{\circ} \mathrm{C}$, to ensure that the sample surface was smooth, before being gradually cooled to ambient temperature for SEM analysis. At least two replicates of each analysis were performed.

\subsubsection{Rheological Performance Analysis}

Dynamic Shear Rheometer (DSR) analyses were conducted to investigate the rheological performance of the rejuvenated asphalt binder. The rheological analyses were performed at a frequency of $10 \mathrm{rad} / \mathrm{s}(1.59 \mathrm{~Hz})$ at temperatures of between 30 and $80^{\circ} \mathrm{C}$, according to AASHTO PP6 specification. Measurements of the complex shear modulus $\left(G^{*}\right)$ and phase angle $(\delta)$ were obtained during the analyses, and at least three replicates of each analysis were performed.

\subsubsection{Toughness and Tenacity Analysis}

Toughness and tenacity performance was analyzed to evaluate the characteristics of internal cohesive force in the asphalt binder during deformation. The samples were imbedded in a container with a hemispherical tension head, and the head was then pulled at a rate of $50 \mathrm{~cm} / \mathrm{min}$, at a temperature of $25^{\circ} \mathrm{C}$, to produce a force-deformation curve according to the JTG E20-2011 standard [25]. The analyses were conducted using a Toughness and Tenacity Tester (SYD-0624), and at least three replicates of each analysis were performed. During the test, toughness and tenacity curves for the rejuvenated asphalt binder were obtained.

\subsubsection{Force-Ductility Analysis}

Force-ductility analysis was conducted to evaluate the deformation resistance capacity of the samples at a temperature of $5{ }^{\circ} \mathrm{C}$, to investigate the durability of recycled pavement material at low in-service temperatures. This analysis was conducted using a Ductility Testing Machine with a dynamometer and data collector (tensile rate of $5 \mathrm{~cm} / \mathrm{min}$, sample insulation for $2 \mathrm{~h}$ at a temperature of $5{ }^{\circ} \mathrm{C}$ before testing) equipped, and at least three replicates of each analysis were performed. During the test, force-ductility curves for the asphalt samples was obtained. 


\section{Results}

\subsection{Gel Permeation Chromatography Analysis}

The molecular weight distribution curves for the samples of aged asphalt binder, virgin asphalt binder, and the corresponding rejuvenated samples (by using CR, MR-1 and MR-2), are presented in Figure 4. Compared with the aged samples, the proportion of smaller molecular weight components increased with different degrees in the D1, D2, and D3 slices. Obviously, the molecular weight distribution changes were caused by the dispersion of rejuvenator with small molecular weight into the aged samples. Therefore, the dispersion capacity and rejuvenated effect of aged asphalt binders can be reflected by the changes degree of GPC curves in D1, D2, and D3 slices. Table 4 shows the calculated correlation coefficients of the GPC curves for different sample depths, and aged sample using a statistical method. Larger correlation coefficients correspond to smaller changes in molecular weight. Table 4 shows that the correlation coefficients of MR-2 was close to that of CR, which mean that the dispersion capacity is similar for MR-2 and CR samples. However, the calculated change in molecular component of MR-1 is significantly smaller than that of MR-2 and CR, which mean that the dispersion capacity of MR-1 is lower than MR-2 and CR.

Table 4. Correlation analysis results of GPC curves.

\begin{tabular}{cccc}
\hline \multirow{2}{*}{ Position } & \multicolumn{3}{c}{ Correlation Coefficient (r) } \\
\cline { 2 - 4 } & CR & MR-1 & MR-2 \\
\hline D1 & 0.969758876 & 0.989985163 & 0.970139281 \\
D2 & 0.988691271 & 0.999302387 & 0.987872939 \\
D3 & 0.999597049 & 0.999829042 & 0.999758177 \\
\hline
\end{tabular}

The molecular weight of the rejuvenator's major composition is below 800, and accordingly, the proportion of the molecular weight below 800 (expressed as M800) was used to quantify changes in molecular weight more directly in this study. The mean values of M800 and their standard deviations are shown in Table 5.

Table 5. Mean values of M800 and their standard deviations of GPC tests.

\begin{tabular}{ccccccc}
\hline \multirow{2}{*}{ Samples } & \multicolumn{2}{c}{ CR } & \multicolumn{2}{c}{ MR-1 } & \multicolumn{2}{c}{ MR-2 } \\
\cline { 2 - 6 } & $\begin{array}{c}\text { Mean Value } \\
\text { of M800 }\end{array}$ & $\begin{array}{c}\text { Standard } \\
\text { Deviation }\end{array}$ & $\begin{array}{c}\text { Mean Value } \\
\text { of M800 }\end{array}$ & $\begin{array}{c}\text { Standard } \\
\text { Deviation }\end{array}$ & $\begin{array}{c}\text { Mean Value } \\
\text { of M800 }\end{array}$ & $\begin{array}{c}\text { Standard } \\
\text { Deviation }\end{array}$ \\
\hline Aged & 28.7 & 1.216 & 28.7 & 1.216 & 28.7 & 1.216 \\
Virgin & 34.1 & 0.925 & 34.1 & 0.925 & 34.1 & 0.925 \\
D1 & 38.8 & 1.053 & 33.7 & 0.931 & 37.7 & 0.832 \\
D2 & 35.0 & 0.921 & 29.9 & 1.823 & 34.8 & 1.056 \\
D3 & 29.8 & 1.336 & 29.4 & 1.521 & 29.2 & 1.228 \\
\hline
\end{tabular}

The M800 values for CR in the D1, D2, and D3 slices were $38.8 \%, 35.0 \%$ and $29.8 \%$, respectively. This result indicates that, compared to the aged sample (which has an M800 value of $28.7 \%$ ), the ratio of substances with a low molecular weight increased, which in turn indicates that the light chemical fractions from the $\mathrm{CR}$ rejuvenator diffused into each slice of aged binder to differing degrees. Moreover, the molecular weight distribution of the D2 slice which was rejuvenated by CR is closest to that of the virgin asphalt. The results show that the D2 slice was effectively rejuvenated, and that CR can restore the chemical composition of aged binder to the levels of the virgin binder. Additionally, MR-2 shows a similar effect to CR, with measured M800 values in the D1, D2, and D3 slices of $37.7 \%, 34.8 \%$, and $29.2 \%$, respectively. This suggests that CR and MR-2 had similar dispersion capacities in the aged asphalt binder. However, the MR-1 rejuvenated sample had significantly lower M800 values in the D2 and D3 slices, which were $29.9 \%$ and $29.4 \%$, respectively. The M800 value in the D1 slice is only 
$33.7 \%$, which indicates that its chemical composition was not restored to the level of the virgin binder. This further indicates that MR-1 did not disperse into the D2 and D3 slices effectively, and that the dispersion ability of MR-1 was lower than that of CR and MR-2.
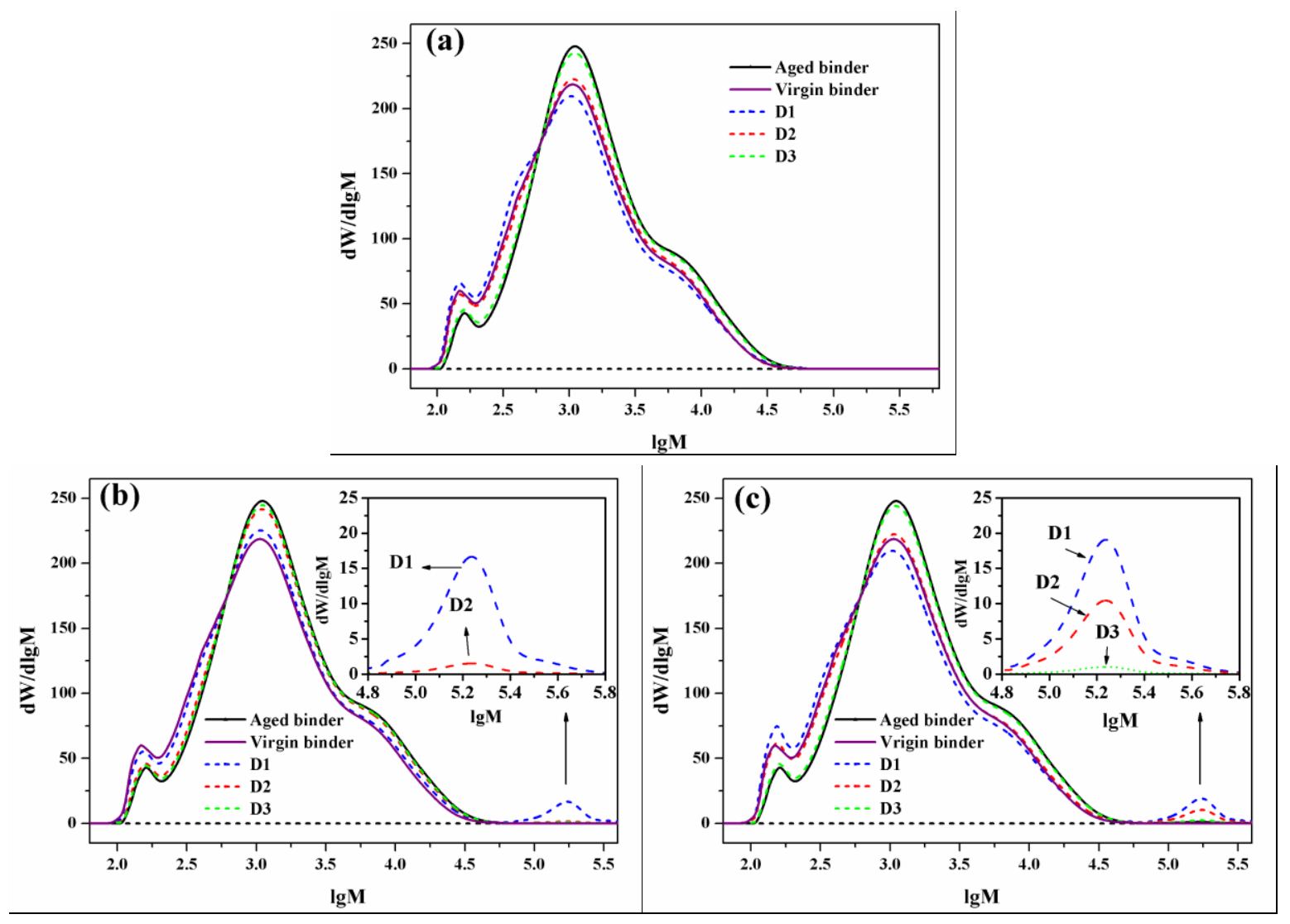

Figure 4. The molecular weight distribution curves for asphalt binder samples: (a) virgin binder, aged binder, CR rejuvenated binder in D1, D2 and D3 slices; (b) virgin binder, aged binder, MR-1 rejuvenated binder in D1, D2 and D3 slices; (c) virgin binder, aged binder, MR-2 rejuvenated binder in D1, D2 and D3 slices.

As can be seen in Figure 4, the curves for the rejuvenated samples using MR-1 and MR-2 contain a new peak in the molecular weight (M) range of 80,000 to 250,000 (the corresponding position in Figure 4 is 4.9 to 5.4 in abscissa). These peaks were caused by the presence of the SBS modifier in the rejuvenators [26,27]. Compared to the aged asphalt binder sample, the MR-2 sample had an obvious change in the D1 and D2 slices, and the MR-1 sample only had an obvious change in the D1 slice.

\subsection{Atomic Force Microscopy Test Results}

As shown in Figure 5a-c, there are numerous continuous peaks in a sequence on the relatively smooth surface. Additionally, as the dispersal depth increases, the peaks increase in intensity. This type of structure is referred to as "bee-like" and is caused by the heterogeneous asphalt colloid structure. This structure can also be distinguished in the phase image (Figure $5 \mathrm{~d}-\mathrm{f}$ ), in which the solid asphaltene particles (black and white streaks) appear to be covered by solid particles of resin (light grey areas) surrounded by an oil matrix (yellow areas), in which asphaltene micelles are dispersed [28]. Compared to the D3 slice, the D1 and D2 slices show fewer contact regions, i.e., the contact area of the 'bee-like' structures (Figure 5f) and smaller 'bee-like' structures $(<4 \mu \mathrm{m})$. Therefore, the addition of the CR rejuvenator increases the development of an oil matrix, and effectively decreases contact phenomena between asphaltene particles. The dispersed asphaltene micelles and continuous oil network lower the cohesive force inside the aged asphalt binder and soften it. 

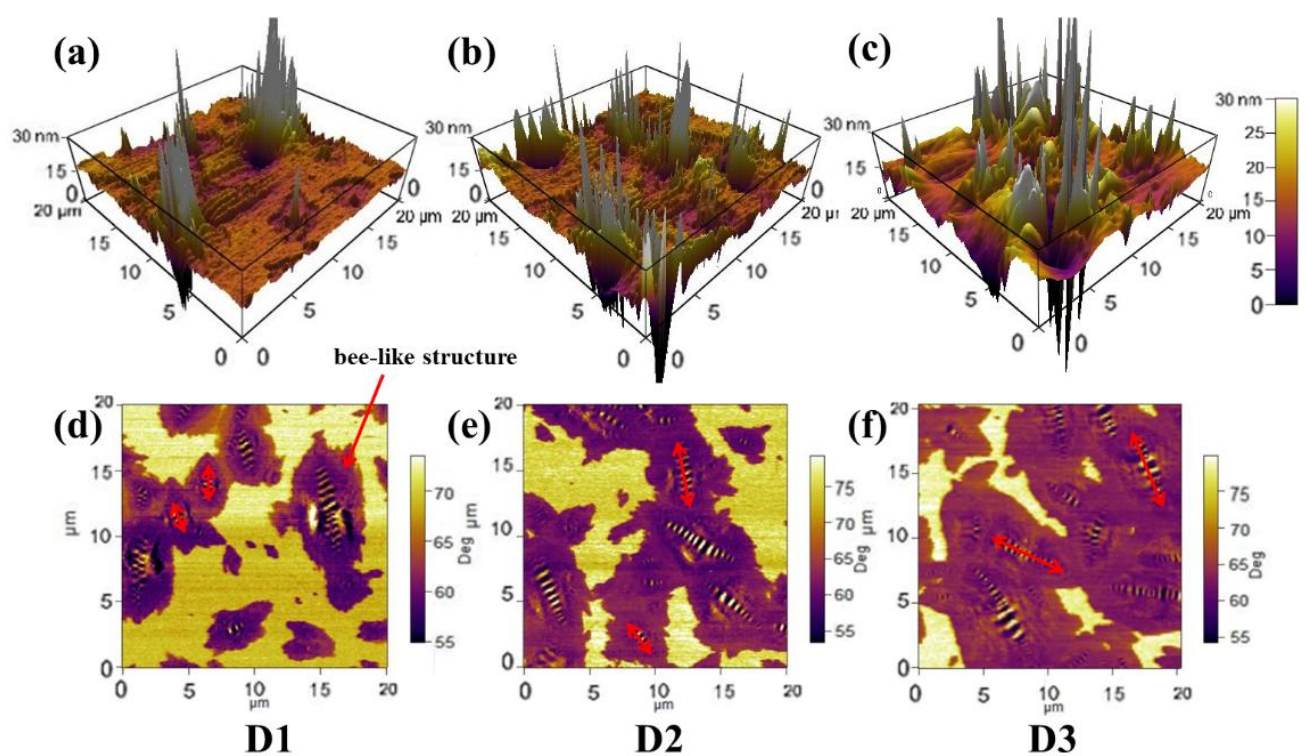

Figure 5. AFM images for the CR rejuvenated sample: (a) 3D height images of D1 slices; (b) 3D height images of D2 slices; (c) 3D height images of D3 slices; (d) phase images of D1 slices; (e) phase images of D2 slices; (f) phase images of D3 slices.

Figure 6 shows the obtained AFM micrographs for the D1, D2, and D3 layers of the MR-1 rejuvenated sample. The D2 and D3 layers show the typical structure of aged asphalt binders. However, in contrast to the results shown in Figure 5, the surfaces of the slices from the MR-1 rejuvenated sample (Figure 6a) were relatively rougher than the D2 and D3 slices from the CR rejuvenated sample (Figure 6b,c), where the MR-1 rejuvenator was not permeated in. Previous research [29] has shown that the appearance of a roughened surface structure is caused by the presence of the SBS modifier, due to the formation of a molecular chain network in the asphalt binder.
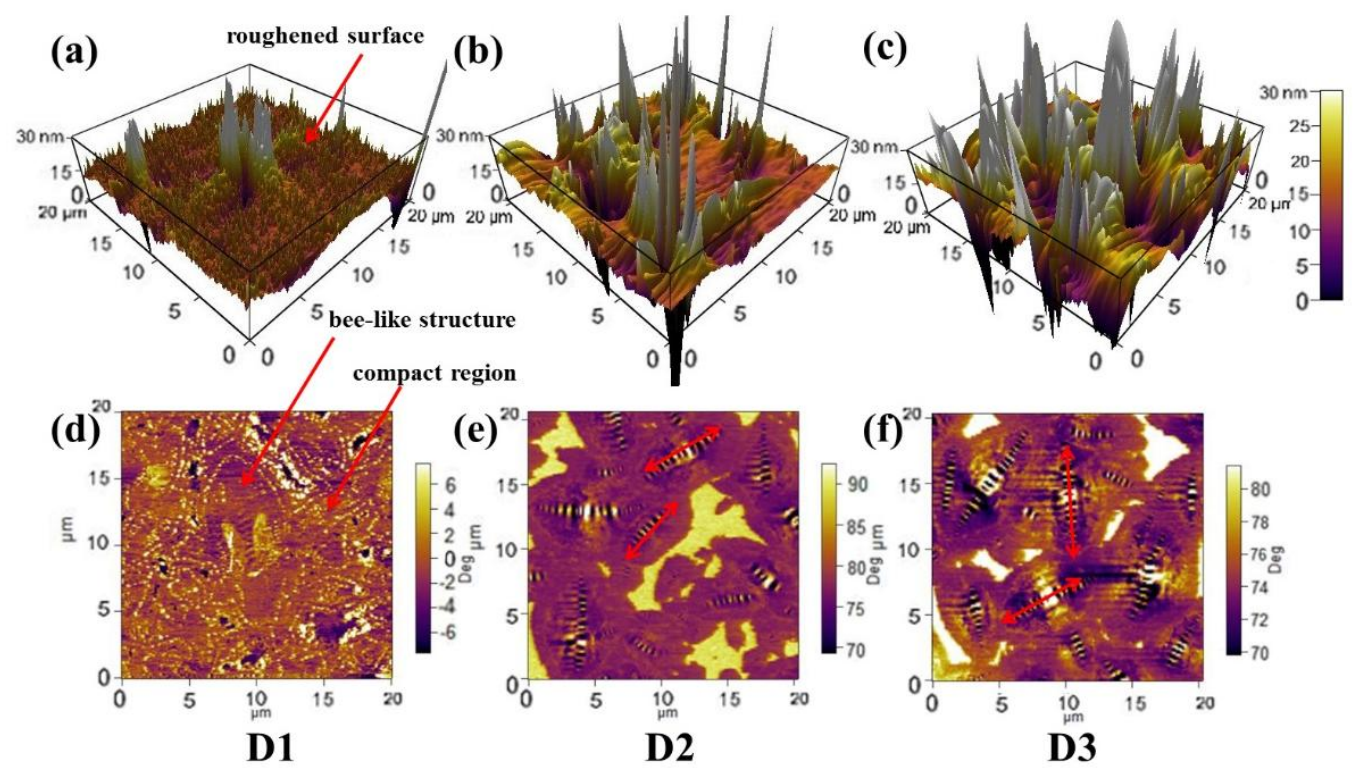

Figure 6. AFM images for the MR-1 rejuvenated sample: (a) 3D height images of D1 slices; (b) 3D height images of D2 slices; (c) 3D height images of D3 slices; (d) phase images of D1 slices; (e) phase images of D2 slices; (f) phase images of D3 slices.

Figure 7 shows the AFM micrographs of the D1, D2, and D3 slices from the MR-2 rejuvenated sample. As in the MR-1 rejuvenated sample (Figure 6a), the D1 and D2 slices from the MR-2 rejuvenated 
sample showed a roughened surface morphology under 3D height mode. Additionally, the 'bee-like' structure in the D1 and D2 slices was smaller $(<4 \mu \mathrm{m})$ and dispersed, as can be clearly observed in the phase images (Figure 7d,e). Furthermore, the contact phenomena between the asphaltenic micelles are less than for the CR and MR-1 rejuvenators. Therefore, comparing the AFM results between the MR-1 and MR-2 samples, the use of dispersing agents in the polymer-modified rejuvenator can be concluded to have significantly improved the colloid structure of the aged asphalt binder.

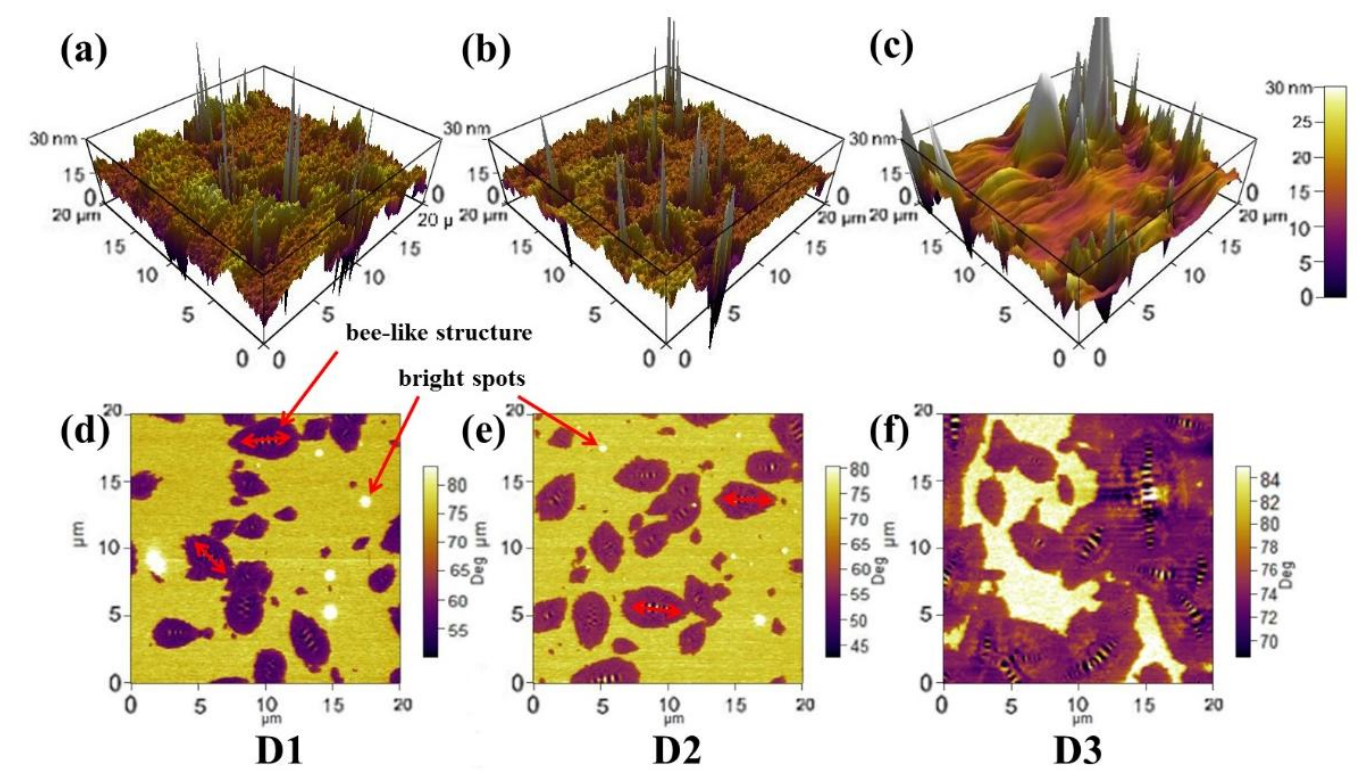

Figure 7. AFM images for the MR-2 rejuvenated sample: (a) 3D height images of D1 slices; (b) 3D height images of D2 slices; (c) 3D height images of D3 slices; (d) phase images of D1 slices; (e) phase images of D2 slices; (f) phase images of D3 slices.

In the AFM results, several bright spots can be observed (Figure $7 \mathrm{~d}, \mathrm{e}$ ). These are distributed relatively uniformly, are differently sized $(0.5-3 \mu \mathrm{m})$, and have a large phase difference compared to other components. Based on the slice number (D1 and D2) and their large phase difference, these bright spots may be caused by the SBS modifier not completely swelling with the light component of the rejuvenator. SEM was subsequently used to confirm the composition of the bright spots.

\subsection{Scanning Electron Microscopy Analysis}

Figure 8 shows the SEM-derived morphologies of the aged asphalt binder, CR rejuvenated asphalt binder, MR-1 rejuvenated asphalt binder, and MR-2 rejuvenated asphalt binder. It can be observed that the aged and CR rejuvenated samples had flat surfaces. The morphologies of the MR-1 and MR-2 rejuvenated samples showed some light grey patches $(0.5 \sim 3 \mu \mathrm{m}$ in size), some of which were raised semicircular particles, and others were as flat as the surface. According to previous SEM research on polymer-modified asphalt binder [30], this appearance is caused by modifier particles, due to the high absorbance of the conglomerate polymer. Additionally, the size of the patches (Figure 8d), and their distribution characteristics, are consistent with the AFM phase images. Therefore, it can be concluded that the bright spots in the AFM phase images were caused by the effect of incomplete swelling with the light component. 

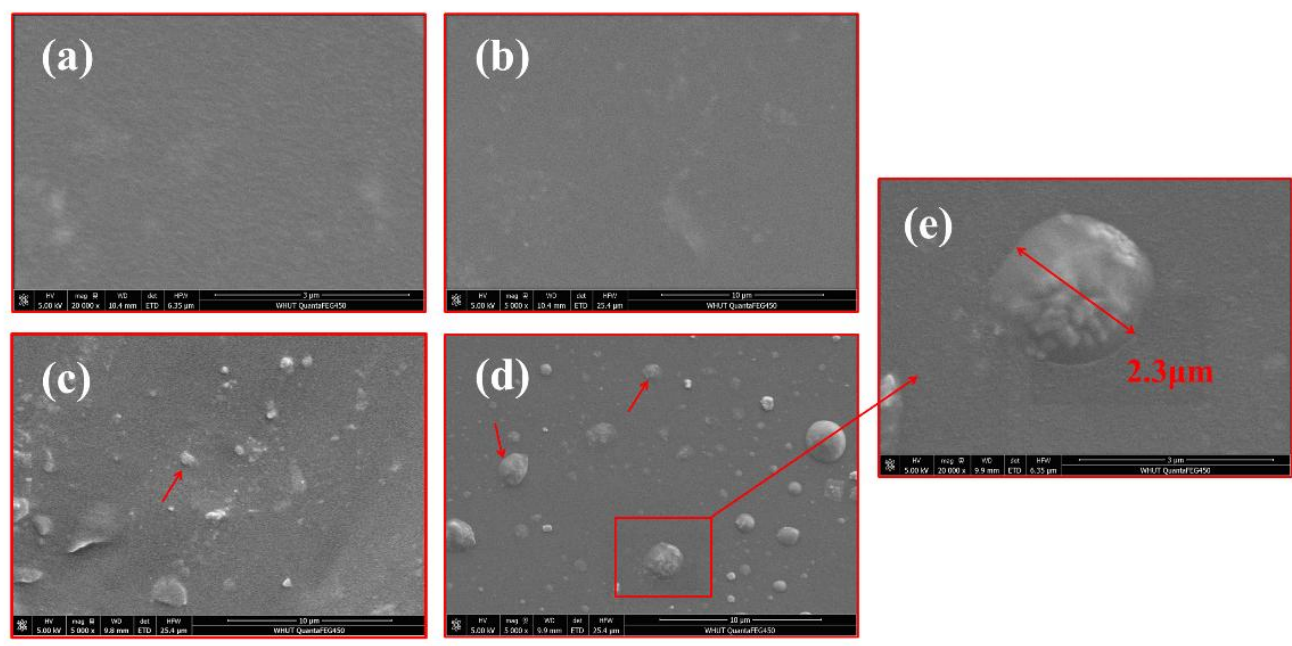

Figure 8. SEM-derived morphology for the different asphalt binders: (a) aged binder $(5000 \times)$; (b) CR rejuvenated binder $(5000 \times)$; (c) MR-1 rejuvenated binder $(5000 \times)$; (d) MR-2 rejuvenated binder $(5000 \times)$; (e) MR-2 rejuvenated binder enlarged $(20,000 \times)$.

\subsection{DSR Analysis}

Figure 9 shows the changes in the complex modulus $\left(\mathrm{G}^{*}\right)$ and phase angle $(\delta)$ of base asphalt binder (AH-70), polymer-modified asphalt binder (1-D), aged asphalt binder, CR rejuvenated asphalt binder $(3 \%, 6 \%, 9 \%)$, and MR-2 rejuvenated asphalt binder $(3 \%, 6 \%, 9 \%)$, with temperature.

In Figure $9 a$, for both rejuvenators, the rejuvenating resulted in a decrease in the $\mathrm{G}^{*}$ for aged asphalt binder. Additionally, as the rejuvenator content increases $(3 \%, 6 \%, 9 \%)$, the decrease range of the $G^{*}$ become greater. This indicates that the addition of the rejuvenators can soften the aged asphalt binder in different degree.

However, it can also be observed that the $\mathrm{G}^{*}$ of the MR-2 rejuvenated sample was higher than that of the $\mathrm{CR}$ rejuvenated sample at a high temperature $\left(50\right.$ to $\left.80^{\circ} \mathrm{C}\right)$ under the same rejuvenator content. Previous studies showed that the asphalt is a temperature sensitive material. Therefore, the test result indicates that the temperature stability of rejuvenated binder with MR-2 is higher than CR samples, and as the increases of MR-2 content, the stability of $\mathrm{G}^{*}$ is more obvious.

Accordingly, in Figure 9b, the phase angle shows a similar changes law to the $G^{*}$, with the different rejuvenator content of $C R$ and MR-2. Nevertheless, there are obvious plateau regions are observable in the phase angle curves, which caused by the stable polymer network structure in MR-2 (9\%) and 1-D asphalt samples at high in-service temperature. When the MR-2 rejuvenator content was reduced, the plateau decreased ( $6 \%$ MR-2 content) and ultimately disappeared ( $3 \%$ MR-2 content), which was due to the weakened network structure with the gradual reduction of polymer content in rejuvenator.

Overall, combined with test results of $\mathrm{G}^{*}$ and phase angle, the asphalt binder rejuvenated with MR-2 has excellent performance of deformation resistance at a high in-service temperature, as with polymer-modified asphalt. On the contrary, the asphalt binder rejuvenated with $C R$ has a relative general performance of deformation resistance at a high in-service temperature. From these curves, it can also be observed that the changes in complex modulus and phase angle with temperature of the MR-2-9\% and CR-9\% samples are closest to that of the 1-D and AH-70 samples, respectively. 

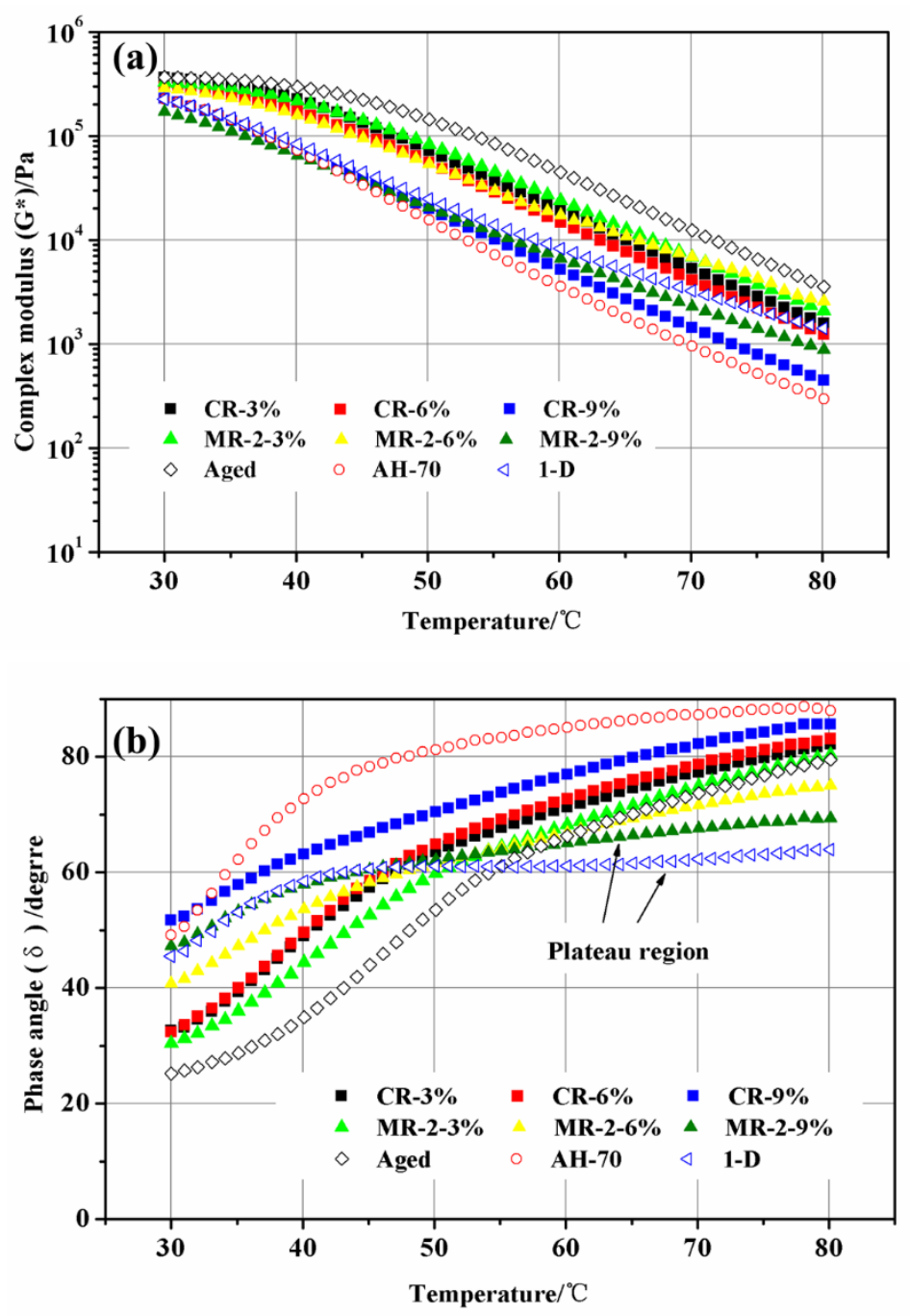

Figure 9. DSR analysis results for CR and MR-2 rejuvenated binders at different contents: (a) curves of complex modulus as a function of temperature; (b) curves of phase angle as a function of temperature.

\subsection{Toughness and Tenacity Analysis}

The toughness and tenacity curve for the $C R$ rejuvenated asphalt binder is shown in Figure 10a. It has been well established that the shape of such curves reflects internal stress changes with tension. The aged asphalt binder in Figure 10a had the typical brittleness characteristic of the material and exhibited a rapid increase in stress and a direct fracture as the deformation increased. It was observed that the CR rejuvenator effectively softened the aged asphalt binder, which changed with the virgin asphalt binder (AH-70) type. Additionally, as shown in Table 6, an increase of the CR rejuvenator content was associated with a gradual reduction in the toughness of the asphalt binder, and an increase in the tenacity of the asphalt binder.

As shown in Figure 10b, the shape of the toughness and tenacity curve for the MR-2 rejuvenated asphalt binder was similar to that of the modified asphalt binder (1-D). There are two obvious characteristics of the toughness and tenacity curve with increasing MR-2 content: (1) The height of the first peak was reduced; and (2) the yielding phenomenon became more evident. The shape of the first peak on the toughness and tenacity curve varied with the properties of the base asphalt binder, and the shape of the yielding region varied with the properties of the modifier [31,32]. The results indicate that the rejuvenated component of MR-2 can soften the aged asphalt binder, and that the modifying components can improve its ability to resist deformation, especially when the MR-2 content was higher than $6 \%$. 

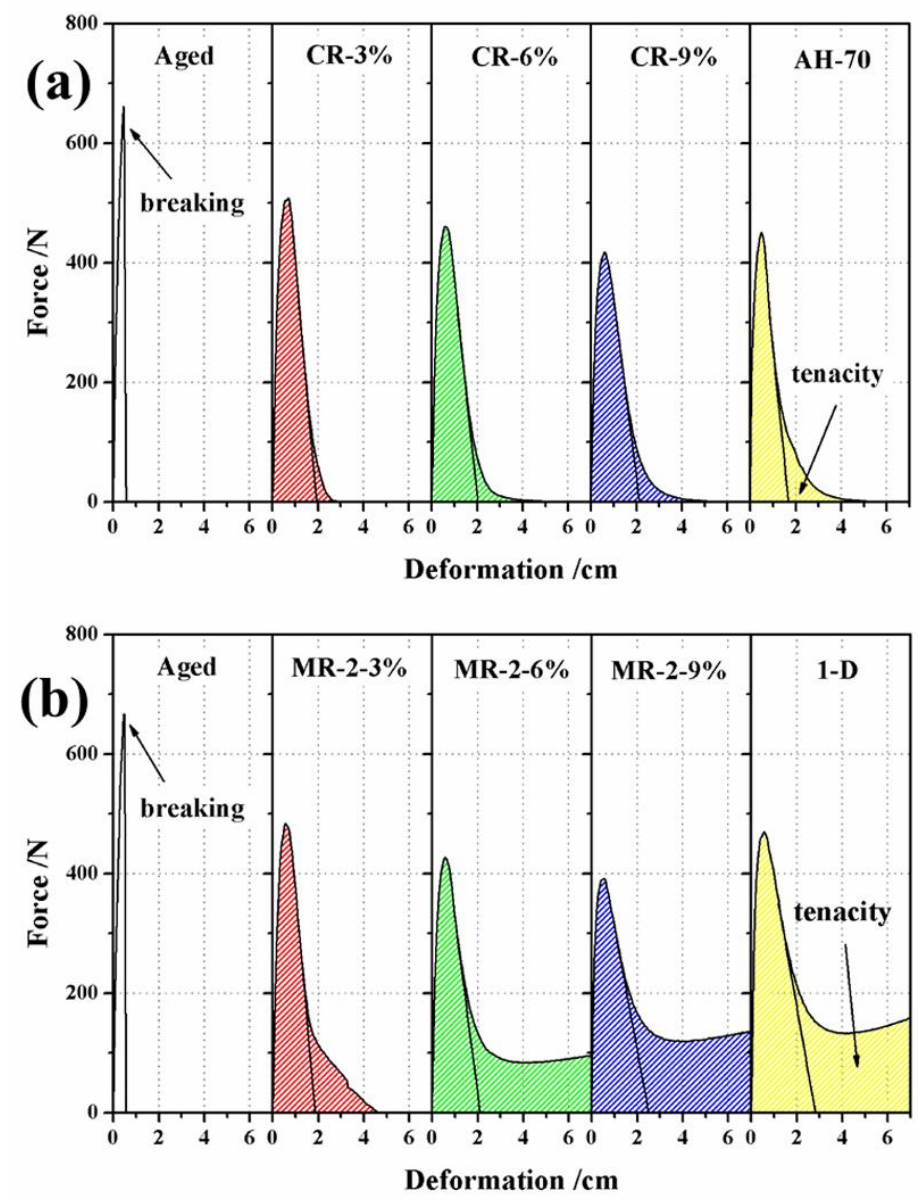

Figure 10. Force-deformation curves for asphalt binder samples: (a) aged binder, virgin binder (AH-70) and CR rejuvenated binder (3\%,6\% and 9\%); (b) aged binder, polymer-modified binder (1-D) and MR-2 rejuvenated binder $(3 \%, 6 \%$ and $9 \%)$.

Table 6. Toughness and tenacity of asphalt binders.

\begin{tabular}{ccccccccc}
\hline \multirow{2}{*}{ Samples } & \multicolumn{9}{c}{ CR } & \multicolumn{5}{c}{ MR-2 } & \multirow{2}{*}{-D } & AH-70 \\
\cline { 2 - 7 } & $\mathbf{3 \%}$ & $\mathbf{6 \%}$ & $\mathbf{9 \%}$ & $\mathbf{3 \%}$ & $\mathbf{6 \%}$ & $\mathbf{9 \%}$ & & \\
\hline Toughness/N·m & 6.21 & 6.03 & 5.75 & 7.61 & 16.31 & 19.23 & 24.46 & 5.42 \\
Standard Deviation & 0.12 & 0.13 & 0.08 & 0.12 & 0.15 & 0.36 & 0.28 & 0.16 \\
Tenacity/ N·m & 0.32 & 0.72 & 0.91 & 1.63 & 11.23 & 15.06 & 19.72 & 1.21 \\
Standard Deviation & 0.08 & 0.05 & 0.09 & 0.09 & 0.31 & 0.46 & 0.51 & 0.08 \\
\hline
\end{tabular}

\subsection{Force-Ductility Test Result}

The force-ductility curves for the CR rejuvenated binder, MR-2 rejuvenated binder, aged binder, and virgin binders is shown in Figure 11. As can be seen in the enlarged image of the beginning tensile section of the force-ductility curve (Figure 11a), most of the samples (including CR-3\%, CR-6\%, CR-9\%, MR- $3 \%$, and aged and virgin samples) experienced brittle fracture immediately after stretching at a temperature of $5{ }^{\circ} \mathrm{C}$, and the ductilities were all less than $1 \mathrm{~cm}$ (see Table 7). The results indicate that those asphalt samples partly lost their viscoelastic behavior, and started to show brittle characteristics at a temperature of $5{ }^{\circ} \mathrm{C}$.

The polymer-modified asphalt (1-D) and MR-2 rejuvenated asphalt (with $6 \%$ and $9 \%$ content) both completed the tensile process at temperatures of $5{ }^{\circ} \mathrm{C}$. The complete force-ductility curve is shown in Figure $11 \mathrm{~b}$. In addition to the ductility, the force-ductility curve can be reflected by two significant indices, i.e., the maximum tension force (Point $\mathrm{A}$ in Figure 11) and fracture tension force (Point B in 
Figure 11). As is shown in Figure $11 \mathrm{~b}$ and Table 7, the 1-D sample has the highest ductility, tension force, and fracture tension force, which indicates that its deformation resistance ability is improved by a polymer network in the asphalt material structure at a temperature of $5{ }^{\circ} \mathrm{C}$, and that the risk of cracking failure was reduced at low in-service temperatures. The force-ductility curve of the MR-2-9\% rejuvenated binder is similar to that of the 1-D sample, and the ductility, maximum tension force, and fracture tension force of the MR-2-9\% rejuvenated binder were relatively lower than those of the 1-D sample. Moreover, as the content of the polymer-modified rejuvenator reduced to $6 \%$, the ductility, maximum tension force and fracture tension force were further decreased, and the internal force of resistance to deformation was also gradually decreased before the sample underwent fracture.

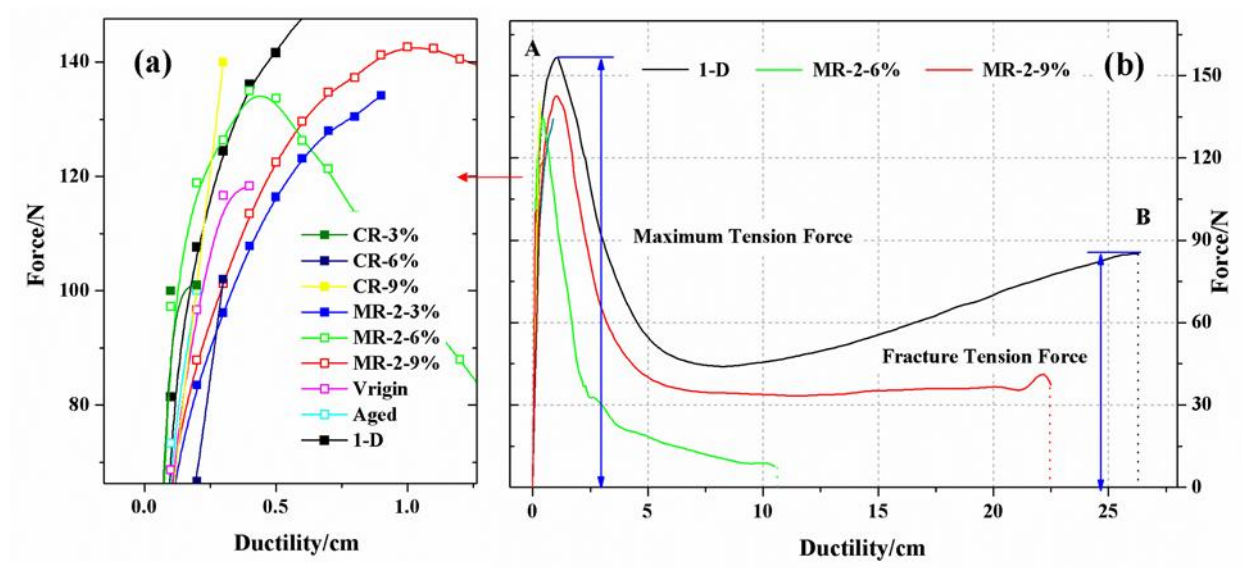

Figure 11. Force-ductility curves for the aged asphalt, virgin asphalts, and rejuvenated asphalts at a temperature of $5{ }^{\circ} \mathrm{C}$ : (a) The enlarged image of the beginning stretch section of the force-ductility curves; (b) The complete force-ductility curves image of the 1-D, MR-2-6\%, and MR-2-9\% samples at a temperature of $5{ }^{\circ} \mathrm{C}$.

Table 7. Force-ductility analysis results for the aged, virgin, and rejuvenated asphalt binders.

\begin{tabular}{cccccccccc}
\hline \multirow{2}{*}{ Sample } & \multicolumn{3}{c}{$\mathbf{C R}$} & \multicolumn{3}{c}{ MR-2 } & \multirow{2}{*}{ Aged } & \multirow{2}{*}{ Virgin (AH-70) } & 1-D \\
\cline { 2 - 7 } & $\mathbf{3 \%}$ & $\mathbf{6 \%}$ & $\mathbf{9 \%}$ & $\mathbf{3 \%}$ & $\mathbf{6 \%}$ & $\mathbf{9 \%}$ & & & \\
\hline Ductility/cm & $<1.0$ & $<1.0$ & $<1.0$ & $<1.0$ & 10.5 & 22.5 & $<1.0$ & $<1.0$ & 26.3 \\
Maximum tension force/N & 101.2 & 102.5 & 139.8 & 134.1 & 135.1 & 142.6 & 98.8 & 116.5 & 156.6 \\
Fracture tension force/N & 101.2 & 102.5 & 139.8 & 134.1 & 7.6 & 37.3 & 98.8 & 116.5 & 85.2 \\
\hline
\end{tabular}

\section{Discussion}

The dispersion behavior of rejuvenators directly affects their rejuvenating effectiveness in aged asphalt binder. There are many factors that can promote or obstruct this dispersion behavior, such as the effective diffusivity, viscosity, interfacial tension, molecular group structure, etc. In this study, we have proposed a multi-component rejuvenator with polymer modifiers to improve the performance of rejuvenated binders. In general, the dispersive ability of CRs is considered to be enough for the process of pavement recycling. However, the dispersive ability of the MR-1 rejuvenator, which directly compounded the SBS modifier with extracted oil, was observed to decrease significantly compared with CR. The GPC analysis showed that, as the dispersing agent was added to MR-1, the dispersive ability of the polymer-modified rejuvenator was improved to the level of CR. Based on the results of the analysis, there are two reasons for this phenomenon: (1) The dispersing agent reduced the viscosity of the rejuvenator from $5.36 \mathrm{~Pa} \cdot \mathrm{s}$ to $2.21 \mathrm{~Pa} \cdot \mathrm{s}$ at a temperature of $135^{\circ} \mathrm{C}$, and increased its dispersion rate in the aged asphalt binder; (2) As other studies have shown, the asphaltene micelles which bonded in the asphalt colloid structure provided the main dispersion resistance against the rejuvenator [33]. In asphalt structures, the asphaltene associated by hydroxyl hydrogen bond and agglomerate to form asphaltene micelles. The polar groups in the methacrylate quaternary copolymer (the principal constituent of the dispersing agent) can form carboxyl hydrogen bonds with asphaltene, 
and the binding force of carboxyl hydrogen bonds is stronger than that of hydroxyl bonds [34]. Thus, the agglomerate structure of asphaltene is partly broken, which is evidenced by the smaller asphaltene micelles observed in the AFM analysis (see Figure 7d,e), and the dispersing resistance from the molecular group structure is reduced.

Based on the results of the DSR, toughness and tenacity, and force-ductility analyses, the asphalt with polymer-modified rejuvenator exhibits the performance features of modified asphalt material, indicating that asphalt binder which is rejuvenated by polymer-modified rejuvenator could improve the performance of recycled pavement material at high and low in-service temperatures. In summary, the polymer-modified rejuvenator not only dispersed the light components into the aged asphalt binder, but also formed a polymer network which reinforced the aged asphalt binder.

\section{Conclusions}

To better understand the effectiveness of polymer-modified rejuvenators on aged asphalt binders, their dispersal behavior, rheological properties, deformation resistance capabilities, and low temperature properties were measured using GPC, AFM, SEM, DSR, toughness and tenacity, and force-ductility $\left(5^{\circ} \mathrm{C}\right)$ analyses. Based on these results, the following conclusions can be drawn:

(1) A new analysis method for assessing the dispersive ability of rejuvenator in aged asphalt binders is proposed, and determined by molecular weight distribution and AFM imaging at different vertical positions within the asphalt binder;

(2) The dispersion ability of polymer-modified rejuvenator on aged asphalt binder is qualified for the pavement-recycling process. The polar groups in the dispersing agent can form carboxyl hydrogen bonds with asphaltene, and partly break the agglomerate structure of asphaltene to reduce the dispersion resistance from molecular group structure;

(3) Asphalt binder treated with polymer-modified rejuvenator could improve the performance of recycled pavement material at high and low in-service temperatures. The complex modulus at a temperature of $60^{\circ} \mathrm{C}$ is increased from 5190 to $6640 \mathrm{~Pa}$, the tenacity is increased from $0.91 \mathrm{~N} \cdot \mathrm{m}$ to $15.06 \mathrm{~N} \cdot \mathrm{m}$, and the ductility at a temperature of $5^{\circ} \mathrm{C}$ is increased to $22.5 \mathrm{~cm}$.

Author Contributions: M.Z. and Q.D.; Data curation: M.Z.; Formal analysis: M.Z. and F.S.; Funding acquisition: F.S.; Methodology: F.S.; Project administration: Q.D.; Writing—original draft: M.Z.; Writing-review and editing: Q.D.

Funding: This work was supported by the National Natural Science Foundation of China (NSFC) under Grant number 51302198 and Highway Science and Technology Project of Hubei Province.

Acknowledgments: This research was conducted at State Key Laboratory of Silicate Materials for Architectures in China.

Conflicts of Interest: The authors declare no conflict of interest.

\section{References}

1. Im, S.; Zhou, F.; Lee, R.; Scullion, T. Impacts of rejuvenators on performance and engineering properties of asphalt mixtures containing recycled materials. Constr. Build. Mater. 2014, 53, 596-603. [CrossRef]

2. Kou, C.; Xiao, P.; Kang, A.; Mikhailenko, P.; Baaj, H.; Wu, Z. Methods to Evaluate the Aging Grades of Reclaimed Asphalt Binder. Appl. Sci. 2017, 7, 1209. [CrossRef]

3. Bowers, B.F.; Moore, J.; Huang, B.; Shu, X. Blending efficiency of Reclaimed Asphalt Pavement: An approach utilizing rheological properties and molecular weight distributions. Fuel 2014, 145, 63-68. [CrossRef]

4. Stimilli, A.; Ferrotti, G.; Conti, C.; Tosi, G.; Canestrari, F. Chemical and rheological analysis of modified bitumens blended with 'artificial reclaimed bitumen. Constr. Build. Mater. 2014, 63, 1-10. [CrossRef]

5. Han, S.; Chung, H.-W.; Subgranon, T.; Tia, M. Development of Mix Designs for Minimally Refined Reclaimed Asphalt Pavement (RAP) Concrete for Florida Concrete Test Road. Sustainability 2018, 10, 2598. [CrossRef]

6. An, J.; Nam, B.H.; Youn, H. Investigation on the Effect of Recycled Asphalt Shingle (RAS) in Portland Cement Mortar. Sustainability 2016, 8, 384. [CrossRef] 
7. Zargar, M.; Ahmadinia, E.; Asli, H.; Karim, M.R. Investigation of the possibility of using waste cooking oil as a rejuvenating agent for aged bitumen. J. Hazard. Mater. 2012, 233-234, 254-258. [CrossRef] [PubMed]

8. Hesp, S.A.; Shurvell, H.F. Quality Assurance Testing of Asphalt Containing Waste Engine oil. In Proceedings of the International Journal of Pavements Conference, Sao Paulo, Brazil, 9-10 December 2013; pp. 3-12.

9. Álvaro, G.; Erik, S.; Martin, V. Properties of capsules containing rejuvenators for their use in asphalt concrete. Fuel 2012, 90, 583-591.

10. Cao, X.; Cao, X.; Tang, B.; Wang, Y.; Li, X. Investigation on Possibility of Waste Vegetable Oil Rejuvenating Aged Asphalt. Appl. Sci. 2018, 8, 765.

11. Asli, H.; Ahmadinia, E.; Zargar, M.; Karim, M.R. Investigation on physical properties of waste cooking oil-Rejuvenated bitumen binder. Constr. Build. Mater. 2012, 37, 398-405. [CrossRef]

12. Silva, H.; Oliveira, J.; Jesus, C. Are totally recycled hot mix asphalts a sustainable alternative for road paving? Resour. Conserv. Recycl. 2012, 60, 38-48. [CrossRef]

13. Tran, N.H.; Taylor, A.; Willis, R. Effect of Rejuvenator on Performance Properties of HMA Mixtures with High RAP and RAS Contents; NCAT Report 12-05; Auburn University: Auburn, AL, USA, 2012.

14. Shen, J.; Amirkhanian, S.; Tang, B. Effects of rejuvenator on performance-based properties of rejuvenated asphalt binder and mixtures. Constr. Build. Mater. 2007, 21, 958-964. [CrossRef]

15. Cheng, Y.; Wang, W.; Tan, G. Assessing High- and Low-Temperature Properties of Asphalt Pavements Incorporating Waste Oil Shale as an Alternative Material in Jilin Province, China. Sustainability 2018, 10, 2179. [CrossRef]

16. Walubita, L.F. Comparison of Fatigue Analysis Approaches for Predicting Fatigue Lives of Hot-Mix Asphalt Concrete (HMAC) Mixtures. Ph.D. Thesis, Texas A\&M University, College Station, TX, USA, 2006.

17. Yu, X.; Zaumanis, M.; Dos Santos, S.; Poulikakos, L.D. Rheological, microscopic, and chemical characterization of the rejuvenating effect on asphalt binders. Fuel 2014, 135, 162-171. [CrossRef]

18. Moghaddam, T.B.; Baaj, H. The use of rejuvenating agents in production of recycled hot mix asphalt: A systematic review. Constr. Build. Mater. 2016, 114, 805-816. [CrossRef]

19. Shen, J.; Amirkhanian, S.; Miller, J.A. Effects of Rejuvenating Agents on Superpave Mixtures Containing Reclaimed Asphalt Pavement. J. Mater. Civ. Eng. 2007, 19, 376-384. [CrossRef]

20. Romera, R.; Santamaría, A.; Peña, J.J.; Muñoz, M.E.; Barral, M.; García, E.; Jañez, V. Rheological aspects of the rejuvenation of aged bitumen. Rheol. Acta 2006, 45, 47-48. [CrossRef]

21. Donya, A.; Colina, J.; Bruneaub, D. Reclaimed asphalt concretes with high recycling rates: Changes in reclaimed binder properties according to rejuvenating agent. Constr. Build. Mater. 2013, 41, 171-181. [CrossRef]

22. Miliutenko, S.; Bjorklund, A.; Carlsson, A. Opportunities for environmentally improved asphalt recycling: The example of Sweden. J. Clean. Prod. 2013, 43, 56-65. [CrossRef]

23. Zhang, D.; Qu, Y.; Zhao, Y.; Xu, Q. The feasibility analysis of modify the recycled asphalt. Pet. Asph. 2010, $22,69-71$.

24. Huh, J.D. Temperature-Adjusted and Modified Recycled Ascon Composition for Reusing 100\% of Waste Ascon for Road Pavement and Method for Manufacturing Same. U.S. Patent US20120167802A1, 7 March 2012.

25. China Communications Press. JTG E20: 2011, Standard Test Methods of Bitumen and Bituminous Mixtures for Highway Engineering; China Communications Press: Beijing, China, 2011.

26. Sun, L.; Wang, Y.Y.; Zhang, Y.M. Aging mechanism and effective recycling ratio of SBS modified asphalt. Constr. Build. Mater. 2014, 70, 26-35. [CrossRef]

27. Liu, G.; Nielsen, E.; Komacka, J.; Greet, L.; van de Ven, M. Rheological and chemical evaluation on the ageing properties of SBS polymer modified bitumen: From the laboratory to the field. Constr. Build. Mater. 2014, 51, 244-248.

28. Carrera, V.; Partal, P.; García-Morales, M.; Gallegos, C.; Páez, A. Influence of bitumen colloidal nature on the design of isocyanate-based bituminous products with enhanced rheological properties. Ind. Eng. Chem. Res. 2009, 48, 8464-8470. [CrossRef]

29. Wu, S.; Pang, L.; Mo, L.; Chen, Y.; Zhu, G. Influence of aging on the evolution of structure, morphology and rheology of base and SBS modified bitumen. Constr. Build. Mater. 2009, 23, 1005-1010. [CrossRef]

30. Zhu, J.Q.; Birgisson, B.; Kringos, N. Polymer modification of bitumen: Advances and challenges. Eur. Polym. J. 2014, 54, 18-38. [CrossRef] 
31. McNally, T. Polymer Modified Bitumen-Properties and Characterization; Woodhead Publishing: Cambridge, UK, 2011.

32. Gao, J.; Wang, H.; You, Z.; Hasan, M.R.M.; Lei, Y.; Irfan, M. Rheological Behavior and Sensitivity of Wood-Derived Bio-Oil Modified Asphalt Binders. Appl. Sci. 2018, 8, 919. [CrossRef]

33. Kuang, D.L. Preparation of Diffusible Rejuvenator and Its Influence on Performances of Recycled Bitumen and Recycled Asphalt Mixture. Ph.D. Thesis, Wuhan University of Technology, Wuhan, China, 2012.

34. Song, H. Study on Synthesis Technology and Evaluation of Viscosity Reduction Copolymer Based on Long Chain Methacrylate. Master's Thesis, Shandong University, Jinan, China, 2011.

(C) 2018 by the authors. Licensee MDPI, Basel, Switzerland. This article is an open access article distributed under the terms and conditions of the Creative Commons Attribution (CC BY) license (http:/ / creativecommons.org/licenses/by/4.0/). 